\title{
Design vernacular como instância criativa: brinquedos artesanais de marisqueiras de Salvador/BA
}

\author{
Vernacular design as a creative instance: handmade toys by female shellfish catchers \\ from Salvador/BA
}

SANTOS, Tamires; Mestre em Desenho, Cultura e Interatividade pela UEFS; Universidade Federal da Bahia (professora titular)

tamilima.santos@gmail.com

SANTANA, Marise; Titulação; Pós Doutora pela UNICAMP; Universidade Estadual da Feira de Santana (professora da Pós-Graduação em Desenho, Cultura e Interatividade)

nabaia@ig.com.br

\section{Resumo}

Este artigo é o resultado de uma dissertação de mestrado que investigou como eram feitos os brinquedos artesanais de marisqueiras da Colônia de Pescadores e Aquicultores Z-67 localizada em Salvador-BA. O objetivo deste artigo é reconhecer os traços do design vernacular presentes nos brinquedos artesanais; considerando o fazer projetual a partir dos materiais e conhecimento nativo, mas principalmente do imaginário e do contexto cultural pertencente a essas pessoas. $\mathrm{A}$ metodologia é baseada no método etnográfico, utilizando-se de entrevistas semiestruturadas com marisqueiras, relatos da infância, reconstrução dos brinquedos e análises dos brinquedos a partir de metodologias do design. Portanto, percebeu-se a carência do reconhecimento e da valorização desses saberes. Conclui-se os brinquedos artesanais das marisqueiras validam como os indivíduos são criativos e capazes de criar dependendo de uma necessidade específica.

Palavras Chave: brinquedo artesanal, design vernacular, contexto cultural.

\begin{abstract}
This article is the result of a master's thesis that investigated about handmade toys by "marisqueiras" (female shellfish catcher) from Colony of fishermen and Aquaculture Z-67, located in Salvador-BA. The aim of this article is to recognize the features of vernacular design present in artisanal toys; considering the projectual make from the materials and native knowledge, but mainly of the imaginary and the cultural context pertaining to these people. The methodology is based on the ethnographic method, using semi-structured interviews with "marisqueiras" (female shellfish catcher), toy reconstruction and analysis of toys based on design methodologies. Therefore, the lack of recognition and appreciation of these knowledge was perceived. It is concluded that everyone can create depending on a specific need.
\end{abstract}

Keywords: handmade toy, vernacular design, cultural context. 


\section{Introdução}

O brinquedo é o primeiro objeto da vida humana e serve para ajudar a criança a desenvolver o corpo, o espírito e o sentimento. Desde os primórdios das civilizações, são encontrados registros dos brinquedos que acompanharam as crianças daquele tempo e que após as transformações materiais e o surgimento da noção de infância no século XVII, permanecem como um dos elementos mais importantes para o desenvolvimento do ser humano.

Existem brinquedos atuais que, na verdade, foram inventados há séculos e milênios de anos atrás, como o ioiô (500 a.C., Grécia) e as bolas de gude (1000 a.C., Egito) encontradas nos túmulos das crianças egípcias. Também existem os que não foram criados intencionalmente para serem brincados, mas, com o passar do tempo, ganharam essa função. Têm-se, por exemplo, a pipa (5000 a.C., China), que servia como sinal de comunicação durante as guerras, e a boneca, que era um tipo de escultura que acreditavam ser capaz de trazer fertilidade para as mulheres.

Antes da chegada da indústria dos brinquedos, eles eram feitos em casa por familiares e pelas crianças, que aprendiam olhando como fazer o brinquedo. Esses brinquedos são conhecidos como brinquedos artesanais e são construídos com materiais domésticos acessíveis como latas, madeira, garrafas e tecidos além de conhecimentos empíricos. Tais conhecimentos advindos da memória e de saberes não-acadêmicos fazem parte do design vernacular.

Essa vertente do design baseia-se nos saberes nativos das pessoas, que encontram soluções criativas, materiais e tecnológicas para desenvolver artefatos de acordo com necessidades circunstanciais e anseios desejados (BOUFLEUR, 2006). A palavra vernacular significa nativo, logo o design vernacular baseia-se em saberes da cultura de seu criador.

Relacionados ao conceito de cultura material como um "conjunto de artefatos produzidos ou usados por determinado grupo ou determinada sociedade" (DENIS, 1998, p.19), vê-se na produção de brinquedos o uso da chamada tecnologia apropriada, "[...]tecnologia criada localmente, de preferência através de meios locais para necessidades locais", conforme expressa Bonsiepe (1983, p.20), ao defender a utilização de tecnologias desenvolvidas localmente.

Conhecer pessoas que faziam brinquedos na infância é uma maneira de resgatar memórias e dar importância a essa prática artesanal. Esse registro é necessário para preservação de um patrimônio cultural material e imaterial e o reconhecimento de tecnologias desenvolvidas localmente. Por isso, foi essencial conhecer as marisqueiras na Colônia de Pescadores Z-67 em Paripe, bairro de Salvador-BA. Elas fazem parte de um grupo cultural especial para essa pesquisa devido a sua relação com o trabalho manual e sua forte relação com a natureza. Desde crianças, elas perpetuam um saber tradicional de mariscar nos rios e mares, normalmente aprendidos com suas mães e outros familiares. Como moravam perto dos rios e longe das cidades grandes, havia entre suas práticas manuais o ato de fazer seus próprios brinquedos. Até hoje, algumas delas criam objetos lúdicos: brinquedos e itens decorativos, nos quais apresentam influências do mar em suas criações.

Esta pesquisa buscou compreender como estes brinquedos eram feitos e seu reconhecimento como produtos do design vernacular. Sendo uma validação de sua importância como elementos da cultura material de um povo, no qual estão impressos uma visão de mundo, anseios e vontades, tem-se que o brinquedo artesanal é uma forma da expressão que carece de registro, análise e interpretação como um patrimônio cultural. 


\section{O CAMINHO METODOLÓGICO}

Com um menor estímulo em fazer seu próprio brinquedo, a criança de hoje consome mais do que cria. Apesar de, em ambos os casos, ter havido a brincadeira, só na primeira situação (o brinquedo feito) há a interação e ressignificação do material, que pode ser vista por diversos olhares, como o design (necessidade, projeto, confecção, materiais, público-alvo), o pedagógico (interação da criança, criatividade, raciocínio lógico) e a cultura (saberes, habilidades e tradições).

É perceptível como esses objetos lúdicos fazem parte do imaginário do indivíduo e relacionam-se diretamente com o contexto cultural no qual está inserido. Para tanto, busca-se conhecer o processo de construção de brinquedos que um grupo de senhoras marisqueiras faziam quando eram crianças. Esta pesquisa faz uso do método etnográfico e, para tanto, a pesquisadora participou constantemente das reuniões das marisqueiras da Colônia de Pescadores e Marisqueiras Z-67, além de visitar a casa das entrevistadas para conhecê-las e estudar o tema com profundidade. Na entrada em campo, a técnica adotada foi realizar entrevistas semi-estruturadas sobre as histórias da infância com dez marisqueiras da Colônia. Após as entrevistas, houve a confecção de brinquedos e a análise interpretativa dos dados dividindo-a em duas etapas: análise histórico-cultural e análise através do design.

A análise histórico-cultural correspondeu à reflexão sobre as condições históricas e culturais das marisqueiras que influenciaram a criação destes brinquedos, explorando conceitos como o surgimento do termo infância e as influências indígenas e africanas na formação da infância brasileira. Já a análise do design tratou de comparar esses brinquedos como produtos do design vernacular, considerando que esta é a atividade que idealiza, cria e desenvolve objetos, visando a interação humana com o ambiente. Para essa análise foi utilizada a metodologia do Metaprojeto (2010) em que cada brinquedo foi destrinchado para observar quais categorias apresentadas por Moraes (2010) foram utilizadas em sua produção.

A literatura que deu suporte para essa metodologia foi "Pesquisa Social: teoria, método e criatividade", de Minayo (1994), "Ideologia e Cultura Moderna", de Thompson (1998) e Metaprojeto, de Moraes (2010). Viu-se que os brinquedos não são simples formas de lazer infantil, antes estão imbricados numa teia de significados que podem ser interpretados e compreendidos na área do design e da cultura de forma interdisciplinar.

\section{TODOS PODEM CRIAR}

As crianças tem uma enorme capacidade de imaginar e inventar. Quando elas estão livres para brincar, simples objetos são reconfigurados para transformarem-se no artefato lúdico mais importante da infância: o brinquedo. E não é apenas a forma ou aparência dos materiais que mudam de roupagem, mas sim o seu significado.

Assim como o designer, todos nós temos a capacidade de projetar e criar artefatos para atender necessidades específicas. No caso das crianças, observa-se que tal habilidade é uma maneira de recriar o mundo à sua maneira, utilizando o material disponível para construir brinquedos que atendem a uma necessidade lúdica. De acordo com Zumbano (2004) "sementes de frutas, pedras, seixos de madeira, ossinhos de animais, conchas e terra são seus brinquedos. Folhas e cascas de árvores servem de fôrma para o barro. Penas de asas de aves se transformam em objetos para a rica imaginação infantil” (ZUMBANO, 2004, p.232). E assim percebe-se que 
diversos materiais podem se transformar em brinquedos, e a criança dispõe principalmente da imaginação para elaborá-los.

Tem-se que todo material na mão de uma criança pode ser transformado, portanto estimular essas experiências é importante para sua formação sociocultural e é preciso deixá-la à vontade para seguir sua imaginação. Deixar a criança livre para criar é uma prática mais recorrente no passado, tempo este em que o brinquedo artesanal era encontrado com mais facilidade do que atualmente. O brinquedo artesanal é aquele feito a partir de materiais acessíveis como os descartáveis ou naturais, que através da criatividade são reconfigurados e ressignificados.

A relação com o Design se dá pelo foco em atender uma necessidade específica, em que existe o lado técnico, concebido a partir de experimentações empíricas, mas também o seu contexto cultural, a emotividade e o prazer de quem utilizará o artefato. Feitos a partir de saberes nativos, acabam por desenvolver técnicas inovadoras que carecem de atenção por parte da academia e do setor produtivo de tecnologias. Para o design, os brinquedos artesanais são um tipo de artefato, um objeto feito pelo homem a partir de técnicas e ferramentas mecânicas ou industriais (Denis, 1998). E como produtos de design eles apresentam, mesmo que de forma inconsciente, um projeto para sua construção envolvendo aspectos funcionais, técnicos e semânticos que viabilizam sua existência.

O fato dos brinquedos carregarem soluções empíricas traz à luz a importância de investigar o passo-a-passo desse saber. Assim pode-se reconhecer as soluções da marisqueira Joelma, 47 anos, quando fazia a jangada ou o cavalinho de bananeira. Seu conhecimento sobre o comportamento dos materiais é notável quando ela explica o modo de fazer a jangada de bananeira: "precisa amarrar quatro troncos de bananeiras, amarrar elas bem forte e ficar boiando, por que pra gente é um barquinho" e assim demonstra o conhecimento sobre tipo de tronco que flutua na água. Sobre a confecção do cavalinho basta tomar um caule da bananeira, retirar a folha e deixar apenas o talo, fazer dois cortes verticais e abaixar uma das partes, formando o rosto.

Figura 1: Cavalinho com folha de bananeira.
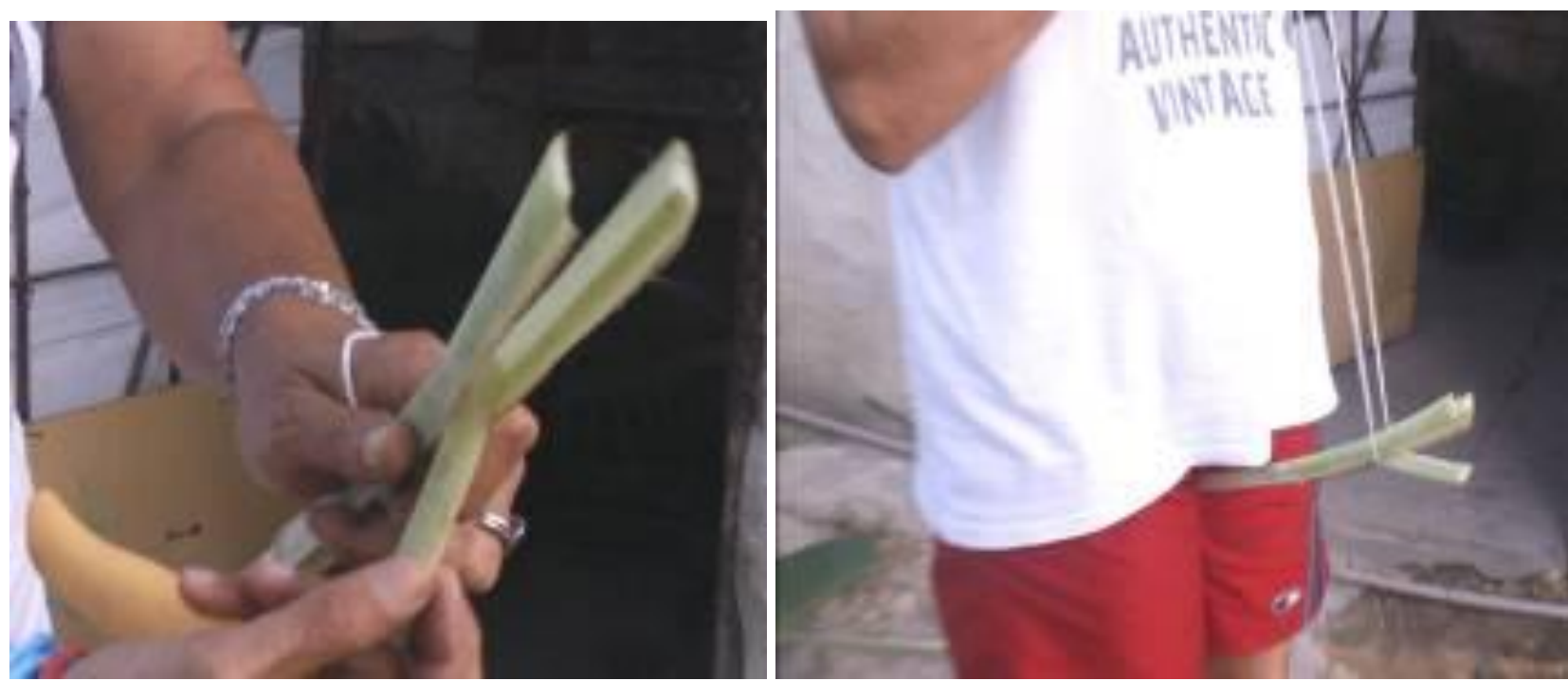

Fonte: Elaborado pela autora, com base na pesquisa realizada 
Todos projetam coisas para usar, comer ou fazer. Assim como os artefatos são utilizados, os indivíduos também pensam e desenham soluções mentalmente e partem da idealização para a concretização na criação ou ajustes de objetos. Para Baynes (1992, p.221) as crianças pensam como designers porque são projetistas e ele acredita que "all small children display a high degree of design ability and use it in their play, ${ }^{1}$. Pois elas pensam no que pretendem construir, alterar ou simplificar dependendo do contexto da brincadeira. Assim pode-se mencionar o carrinho de lata de sardinha que Dona Val fazia na companhia dos irmãos e primos.

\begin{abstract}
A gente ajudava os nossos irmãos né?! Fazíamos carrinhos... Para fazer, pegava a sandália e cortava pra fazer as rodinhas, botava um palito de palha de coqueiro, aí botava aquelas latas de sardinha antigas, furava os buraquinhos e fazia os carrinhos, pegava aquelas tabuinhas velhas, fazia tipo um boleiazinha. Colocava um preguinho e um cordão e eles saiam alegres e satisfeitos puxando e brincando. (D. Val)
\end{abstract}

Observando essas peculiares manifestações de design, alguns pesquisadores encontraram nomenclaturas convenientes. Tais como o artesanato, o brinquedo artesanal pode ser chamado de: "design vernacular, design alternativo, design espontâneo, design popular, design nãocanônico, design não-profissional, pré-design, entre outros" (BOUFLEUR, 2006, p. 49). Essa categoria do design sempre apresenta características locais ou regionais.

Entende-se que o design vernacular apresenta uma série de hábitos e costumes de seus criadores, seus desejos e crenças. Assim, pode-se ver no brinquedo traços da identidade ao invés de meras cópias do brinquedo industrializado. Para CAVALCANTI, V; COUTINHO, S; FINIZOLA, F. (2012) é preciso dar mais atenção a essas produções em meio à dinâmica intensa da indústria, pois muitos detalhes peculiares passam despercebidos.

${ }^{2}$ For those with an eye more attentive to their surroundings, these elements, which often go unnoticed in the constant dynamic rhythms of large urban centers, may reveal certain peculiarities of the habits and customs of a people, their desires, their needs, their ideas, and still express something from the periphery and its counterculture. (FINIZOLA; COUTINHO; CAVALCANTI, 2012, p.1)

Percebe-se que essa produção não possui o devido zelo por parte da academia porque sua importância cultural foi minimizada pelo seu caráter empírico que foge do saber acadêmico. Assim, FINIZOLA; COUTINHO; CAVALCANTI (2012) expõe que as expressões do design vernacular muitas vezes são reconhecidas com valor minimizado, pois são romantizadas como folclore. Porém, tais expressões podem ser analisadas através de conceitos, modelos e teorias para sugerir lições ao design. Dessa maneira, é preciso entender como ocorrem tais processos criativos. Alguns critérios observados por FINIZOLA; COUTINHO; CAVALCANTI (2012) são:

\footnotetext{
${ }^{1}$ Tradução: Todas as criancinhas apresentam um elevado grau de habilidades de design e a usa em suas brincadeiras.

${ }^{2}$ Tradução: Para aqueles com um olho mais atento ao seu ambiente, estes elementos, que muitas vezes passam despercebidos nos ritmos dinâmicos constantes de grandes centros urbanos, pode revelar certas peculiaridades dos hábitos e costumes de um povo, seus desejos, suas necessidades, suas idéias, e ainda expressar algo a partir da periferia e sua contracultura.
} 


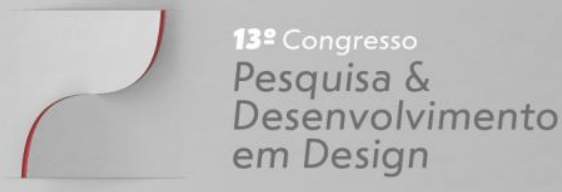

Artigo Completo

Tabela 1 - Processos criativos no design vernacular

\begin{tabular}{|l|l|}
\hline \multicolumn{1}{|c|}{ Critério } & Forma de expressão no Design Vernacular \\
\hline 1. Referência conceitual & Não-acadêmica/Informal \\
\hline 2. Autor & Não-especialista/ Anônimo em alguns casos \\
\hline 3. Planejamento do processo & Intuitivo, mental ou esquemático \\
\hline 4. Processo produtivo & Artesanal. Utiliza material nativo ou reciclado. \\
\hline 5. Usuário final & $\begin{array}{l}\text { Nativo, geralmente vindo da comunidade, a } \\
\text { maioria de classes populares. Algumas vezes os } \\
\text { usuários podem vir de outros grupos. }\end{array}$ \\
\hline 6. Linguagem estética & $\begin{array}{l}\text { Em geral se refere à cultura visual dos subúrbios } \\
\text { e de classes de baixo poder aquisitivo. Revela a } \\
\text { ferramenta e os materiais usados pelo artesão. } \\
\text { Utiliza cores e símbolos do universo popular. }\end{array}$ \\
\hline
\end{tabular}

Fonte: Tradução da autora. Fonte: FINIZOLA; COUTINHO; CAVALCANTI (2012)

Através dessa tabela percebe-se que a produção vernacular se expressa de maneira intuitiva, informal e o usuário normalmente é seu próprio criador ou pessoas da comunidade local. Dessa forma, como surgem para um público e num cenário específico encontram-se mais características próprias desses objetos. É preciso estudar e analisar essa produção do design vernacular porque apesar de apresentar algumas dificuldades operacionais, é possível aplicar tais conhecimentos para o crescimento de um design autêntico com as características de cada país.

\section{A cultura expressa em suas criações}

Para Rapoport(1987), a característica mais interessante dos objetos oriundos do design vernacular é a utilização de materiais específicos do ambiente de seu criador, texturas e cores porque representam elementos étnicos, religiosos, regionais e demais traços de identidade de quem produz e quem consome. Esses produtos trazem grande impacto socialmente e economicamente porque influenciam no ciclo de vida dos objetos, no estilo de vida das pessoas e como movimentam a economia através da compra e venda de produtos.

Assim compreende-se como os brinquedos das marisqueiras se enquadram nessa questão. Eles eram feitos a partir das vivências e materiais encontrados por essas marisqueiras e apresentam sua identidade. Como não possuíam condições econômicas e nem haviam fábricas de brinquedos expressivas na época, expressavam os valores, a cultura e o estilo de vida que levavam. Também é observado que esses saberes produzem artefatos para subsistência de acordo com o cenário cultural que está inserido.

Nessa pesquisa foi analisado como os brinquedos artesanais das marisqueiras foram construídos buscando identificar os traços de idealização, construção de artefatos e semelhanças com o designer profissional. Essa análise foi uma forma de legitimar que assim como o designer, todos os indivíduos são criativos e tem potencial para produzir dependendo de sua necessidade. 0 que se percebe é: os indivíduos são complexos e suas criações também. O trabalho do designer é 
projetar para uma gama de pessoas com culturas, identidades e memórias distintas, já o produtor vernacular cria para sua comunidade ou para si mesmo.

As mulheres deste estudo nasceram entre as décadas de 50 e 70, em que não havia muitas fábricas de brinquedo e as que existiam eram concentradas em vender para as grandes cidades. De acordo com Mefano (2005), a maior fábrica brasileira de brinquedos, chamada Estrella, nasceu em 1937 e fazia apenas bonecas de pano. Logo, fazer os próprios brinquedos eram uma necessidade lúdica. Logo, foi interessante perceber que cada entrevistada trazia soluções ímpares e totalmente relacionadas com o contexto histórico-cultural em que estão inseridas.

Essas constatações se deram ao perceber como as marisqueiras que moravam em cidades com muito barro como Dona Lurdes, construíam casinhas, fogões, panelas e derivados. Já Dona Joelma que mora a beira do mar fazia jangadas e peixinhos. Dona Rosa que morava na capital Salvador, já conhecia os carrinhos de rolimã e Dona Val que morava num sítio, fazia bonecas de milho na época junina, pois este era o período em que os milhos estavam maiores, o que sinaliza também a existência de brinquedos sazonais.

Além de notar que alguns brinquedos tinham épocas para existirem, nota-se também elementos da identidade de cada local e de cada marisqueira. Sendo a identidade uma construção da imagem de si e como se apresenta para os outros, ela parte da interação entre o eu e a sociedade, tendo em vista a aceitação e sua credibilidade pelo grupo de que o individuo faz parte. Como ressalta Hall,"existe sempre algo "imaginário" ou fantasiado sobre sua unidade. Ela permanece sempre incompleta, está sempre "em processo", sempre "sendo formada" (HALL, 2006, p.38). Assim sendo, a identidade está sempre em construção, e tal fator influencia na criação do brinquedo artesanal, que pode receber novos significados a cada brincadeira.

Tem-se também que a produção tem forte ligação com a memória e identidade ligada aos saberes ancestrais. Pode-se notar essa intrínseca relação já que essas mulheres carregam histórias sobre os objetos lúdicos de sua criação, memórias, pertencimento e etnia. Para Ferreira (2005), a identidade social reflete também a etnicidade, como o entendimento dos traços culturais identificadores e diferenciadores dos grupos.

Entende-se que essa prática projetual carrega consigo uma gama de fatores socioculturais que inspiram essa criação. Um objeto criado não tem apenas uma função ou atende a um único problema, e os brinquedos contam a história de seus donos. Relacionando com o design entendese que "[...] design é uma disciplina que não produz apenas realidades materiais, mas especialmente preenche funções comunicativas" (BÜRDEK, 1997, apud BÜRDEK, 2008, p.231). Essa comunicação depende do indivíduo e de que significados lhe são atribuídos, pois que os significados estão relacionados ao contexto cultural. O autor defende que:

As coisas da natureza falam a nós, fazemos com que o artificial fale por nós: eles contam como foram constituídos, que tecnologia foi utilizada, de que contexto cultural tem origem. Eles nos contam também algo sobre os usuários, suas formas de vida, sobre se pertencem de verdade ou fingem pertencer a certos grupos, sobre atitude perante valores. O designer necessita, por um lado, entender esta linguagem, por outro deve fazer as coisas falarem por si sós. Nas formas dos objetos pode se ver e reconhecer as diversas formas de vida. (FORMDISKURS 3, II/1997, apud BÜRDEK, 2008, p. 231).

Assim, tem-se que os objetos refletem o estilo de vida e a identidade de quem os usa. $\mathrm{O}$ autor revela que o indivíduo utiliza objetos de acordo com as mensagens que esse produto expressa. E quanto à criança, quando ela produz seu brinquedo, ela se preocupa em explicitar seu 
imaginário e sua necessidade lúdica e, por um comportamento inerente, expressa sua cultura e os saberes tradicionais de sua família e comunidade. Logo, não é possível pensar no design dissociável de uma cultura.

\section{Brincando com elas}

As mulheres desta pesquisa são residentes do bairro de Paripe e foram encontradas entre as mais de 300 marisqueiras cadastradas na Colônia de Pescadores e Aquicultores Z-67. Após quatro meses de tentativas, foram selecionadas dez marisqueiras na definição de amostragem. Essa escolha foi feita devido à timidez das senhoras em aparecer diante das câmeras, mas também porque o objetivo de encontrar brinquedos com métodos de construção e materiais diversificados já havia sido alcançado, e os discursos já começavam a se repetir. O fator principal dessa busca foi encontrar mulheres cuja infância teve menos contato com as tecnologias dos tempos modernos e menos facilidade em adquirir brinquedos industrializados.

Para conhecer as marisqueiras e seus brinquedos foi utilizado o método etnográfico. Tal método consistiu em conhecer de perto as sujeitas da pesquisa a partir da convivência. Dessa forma, existiram as reuniões na Colônia de Pescadores e Aquicultores Z-67, visitas a domicílio e entrevistas semiestruturadas para conhecer as histórias de infância e métodos para construção dos brinquedos. Após essa etapa, os brinquedos foram analisados a partir de uma metodologia do design, para verificar quais etapas de construção puderam ser encontradas.

Os métodos de análise das tecnologias encontradas nesses brinquedos foram baseados no livro Metaprojeto, de Dijon de Moraes. Segundo essa teoria, os objetos de design precisam ser analisados de acordo com as necessidades básicas e objetivas do usuário, mas, de igual forma, "[...] as necessidades secundárias, derivadas e subjetivas, que dizem respeito à emotividade, ao desejo e ao prazer" (MORAES, 2010, p.26). Esse autor considera que existem diversos fatores que influenciam a atividade projetual. Por isso, faz-se necessária uma reflexão crítica e compreensiva sobre esses produtos gerados em um cenário onde se apresentam os fatores socioculturais, produtivos, tecnológicos, materiais, mercadológicos, ambientais e tipológicos (MORAES, 2010). Sua metodologia é um pacote de conhecimentos que o designer pode utilizar antes da criação de um objeto ou pode ser utilizada para considerar não apenas artefatos já existentes, como também os fatores mencionados, além de expor pontos que necessitam de redesign.

Esses fatores são relacionados ao cenário, isto é, em que ambiente e mercado esse brinquedo foi construído. Existe o aspecto sustentável no qual são analisadas quais tecnologias limpas e materiais causam pouco dano ambiental. Já o fator das influências socioculturais é predominante porque todo produto é influenciado pelo contexto sociocultural que seu criador faz parte. Também existem as questões de produção, material e tecnológica que descrevem os materiais utilizados na produção desses brinquedos, indicando o estado de sua matéria bruta e da matéria-prima, assim como as tecnologias utilizadas no desenvolvimento do projeto. No aspecto tipológico/ergonômico, é importante perceber por que um brinquedo chegou a esse ou aquele resultado. Em suma, parte das necessidades individuais da criança e as formas possuem qualidades "[...] sensoriais, emocionais e psicológicas, que hoje determinam uma melhor interface entre homem/produto/ambiente" (MORAES, 2006, p.7)

Nem todos os aspectos do Metaprojeto foram levados em consideração, pois não 
apresentavam quesitos cabíveis para a análise de uma produção artesanal de brinquedos. Alguns deles buscam explicitar questões de maquinário e reprodução industrial, questões comerciais e de marketing, o que não ocorre nessa produção. Esta análise buscou identificar traços de idealização e construção de objetos, similares à atividade do designer, para defender o ponto de vista de que todos os indivíduos são criativos em potencial e têm capacidade de encontrar soluções materiais e técnicas para construir objetos, dependendo de necessidades específicas. Para tanto, serão apresentadas as análises de três brinquedos desenvolvidos pelas marisqueiras. Nas fotografias já é possível acompanhar os materiais e métodos de construção enquanto que na análise textual temse o cenário, influências socioculturais, sustentabilidade e fatores tipológicos/ergonômicos.

Dona Val

1 - Materiais e Método de construção

Figura 2 - Construção de brinquedo

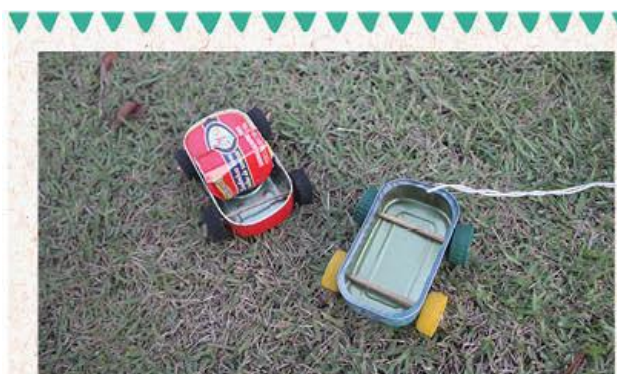

Carro de lata de sardinha

Materiais:

lata de sardinha

2 gravetos

4 tampinhas de garrafa

I sandália de borracha

$150 \mathrm{~cm}$ de barbante

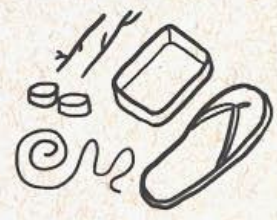

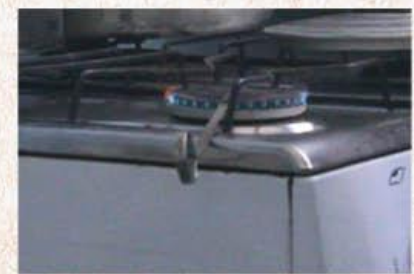

1. Esquente a ponta de uma chave de fenda no fogão

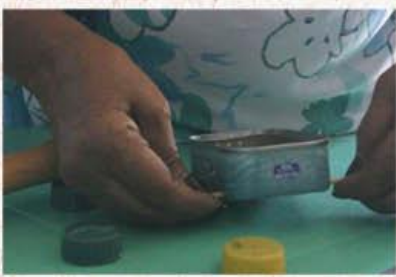

4. Enfie os palitos atravessando os furos.

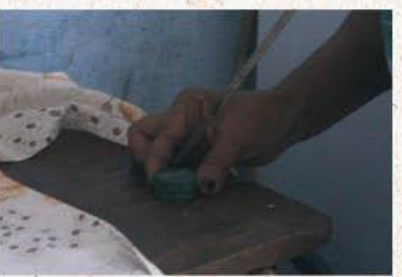

2. Fure as tampinhas ou rodinhas recortadas de borracha.

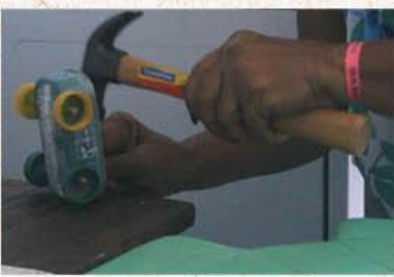

5. Encaixe as rodas.

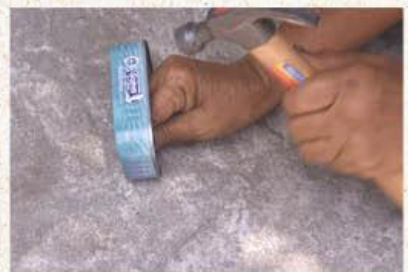

3. Faça 2 furos nos 2 lados maiores da lata

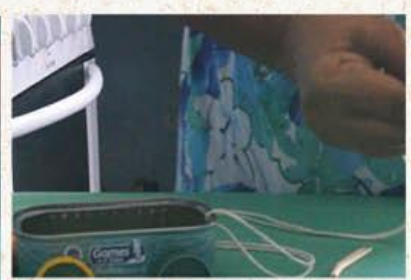

6. Faça um furo na lateral $e$ amarre uma cordinha.

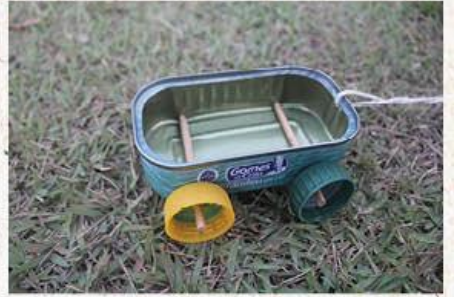

7. Você pode arrancar toda a tampa e ter um carro aberto.

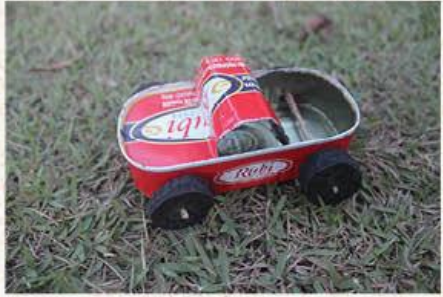

8. Se arrancar metade da tampa terá o banco do morotista. 


\section{Cenário e Influências culturais}

Dona Val morava no interior de Alagoas na cidade de Penedo, e suas brincadeiras foram sempre na companhia de primas, primos e irmãos. A cidade fica nas margens do rio São Francisco e proporciona muitas atividades pesqueiras aos moradores. Quando Dona Val brincava com meninas, ela construía bonecas de pano ou de milho e contava com a ajuda dos meninos para pegar capim no rio para ser o recheio do corpo das bonecas de pano. Quando brincava com os meninos, fazia carrinhos de lata. Dessa maneira, revela-se a separação entre os brinquedos que podiam ser feitos e brincados, dependendo do gênero, desde a infância. Também é percebido o senso de cooperação entre as crianças. Mesmo quando o brinquedo não era para elas, a realização estava em ver o brinquedo confeccionado e, assim, todos ajudavam como podiam.

É possível ver as influências culturais na diferença entre os brinquedos feitos com as meninas e os brinquedos feitos com os meninos e também a mútua cooperação. Quando faziam bonecas de pano os meninos ajudavam a catar capim do fundo dos rios para preencher o corpo das bonecas e, quando estes faziam carrinhos, as meninas ajudavam a procurar latas e sandálias de borracha e, também, a cortá-las. Dona Val também fazia bonecas de milho, porém essas eram sazonais, pois só podiam ser feitas em tempo de São João. Essa cooperação fez D. Val aprender, através da observação, como fazer os carrinhos.

No caso de Dona Val, percebe-se como a cooperação entre os sexos eram essenciais para o êxito nas construções dos brinquedos. Porém, na hora de brincar, os grupos se dividiam novamente. Segundo Thompson (1998, p.185), a utilização e a interpretação das formas simbólicas "[...] são processos que, caracteristicamente, envolvem a aplicação de regras, códigos ou convenções de vários tipos". Dessa forma, o código aplicado nessa situação é que os gêneros masculino e feminino não podiam se misturar na utilização de certos brinquedos. Esse comportamento sexista fazia parte da comunidade em que vivia e era aplicado às crianças.

\section{Sustentabilidade}

Os brinquedos de dona Val envolvem elementos naturais também materiais de descarte como as latas e sandálias quebradas. Neste estudo, ela apresentou o carrinho de lata e o pé-delata, que são brinquedos duráveis feitos a partir do pós-uso de materiais industriais. Como morava no interior e o acesso a esses materiais era mais difícil, a procura de materiais era feita em coletividade pelas crianças, mostrando que todo material de descarte era bem-vindo.

Tipologia e ergonomia

Quanto aos carrinhos, estes eram do tamanho de uma lata de sardinha horizontal, medindo $6 \times 10,5 \mathrm{~cm}$, apresentando pontas arredondadas e com rodas feitas com tampinhas de garrafa ou recorte da sola de sandálias de borracha, com um raio de $3 \mathrm{~cm}$. 


\section{Dona Nadir}

Materiais e Método de construção

Figura 3 - Construção de brinquedo

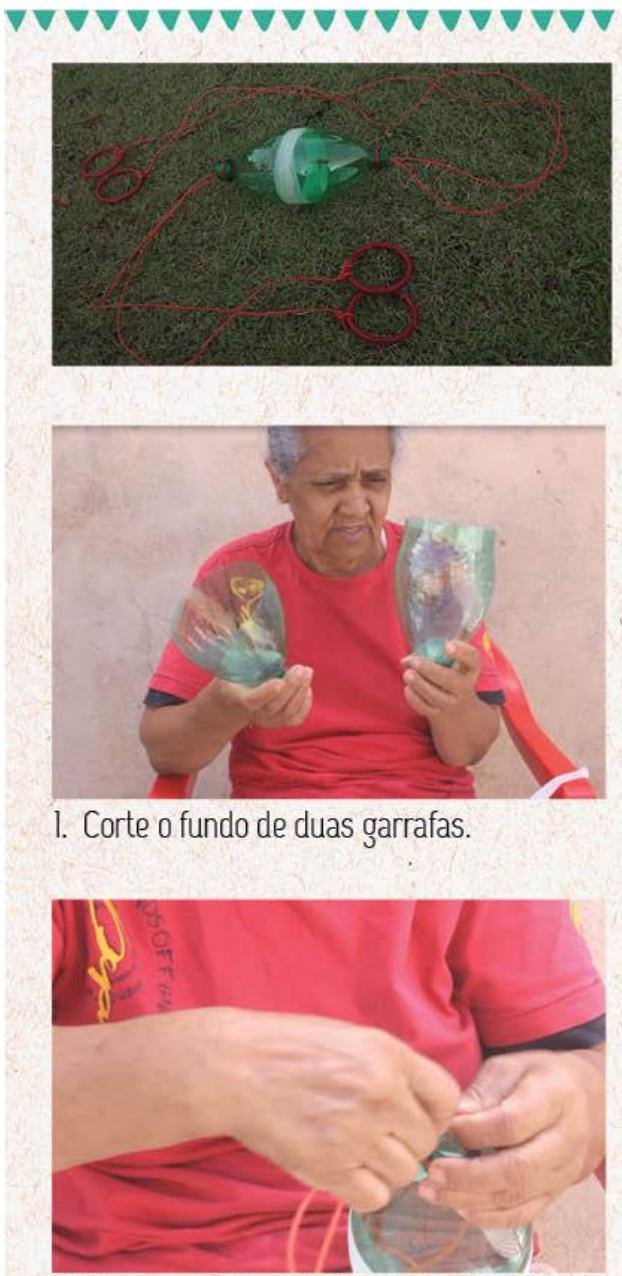

3. Passe o cordão por dentro dos dois furos. Se usar lata, faça furos com pregosos antes.
Vai-e-vem

Materiais:

- 2 garrafas pet ou 2 latas

- 6m de cordão

- 4 argolas de pulseira
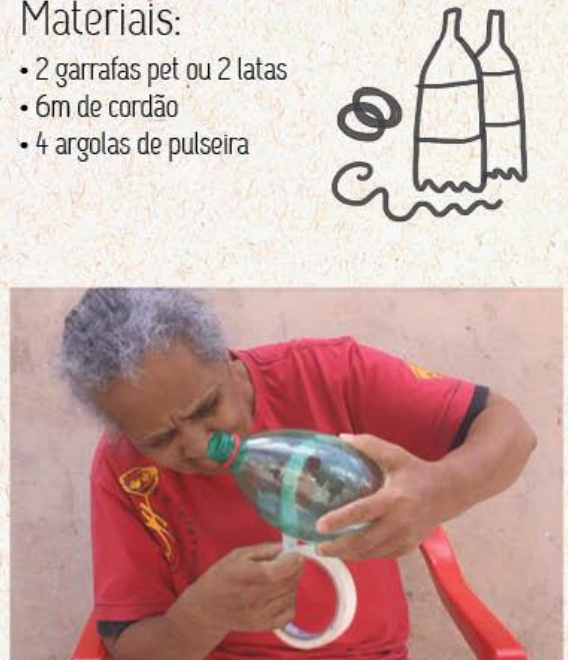

2. Encaixe as duas partes e prenda com fita ou com pregos.

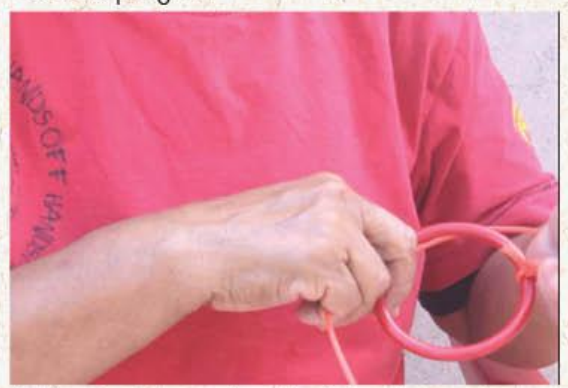

4. Amarre as argolas. Na falta de argुolas, crie alças dando nó na ponta do barbante.

\section{Cenário e Influências socioculturais}

A cidade que nasceu foi Jequié, mas se criou na cidade vizinha Jaguaquara. Ao crescer na roça, o interesse comum dela e de seus irmãos era confeccionar brinquedos sonoros como o telefone sem fio e o vai-e-vem. Os brinquedos de Dona Nadir sempre eram feitos com objetos de descarte como latas, copos e retalhos. Assim percebe-se que a motivação, nesse caso sonora, é crucial nos brinquedos que criavam. Eles não repetiam os brinquedos da vizinhança, pois tinham um objetivo original que os levava a percorrer longas caminhadas na procura dos materiais difíceis de serem encontrados no interior do Estado durante sua infância. 


\section{Sustentabilidade}

O fato da mesma nunca ter comprado um brinquedo demonstra a necessidade do reaproveitamento de materiais para brincar. Na infância, Dona Nadir fazia o brinquedo vai-e-vem com latas encontradas na vizinhança, mas nos tempos atuais ela utiliza garrafas pet e o faz nas atividades infantis da igreja que frequenta. É revelado como os materiais podem mudar no decorrer do tempo dependendo da facilidade de encontrá-los e manuseá-los, mas permanece a função do brinquedo e reutilização de materiais contemporâneos. $O$ interessante é a utilização de matérias-primas com baixo impacto ambiental, fácil montagem/desmontagem e durabilidade.

\section{Tipologia e ergonomia}

O brinquedo é feito com cordas longas para que a lata desloque um percurso mais longo e produzir barulho por mais tempo. Também faziam alças com a corda para maior conforto das mãos que seguram as extremidades do brinquedo. O brinquedo no passado tinha formato cilíndrico e atualmente com a garrafa pet tem forma aproximada de um losango com $13 \mathrm{~cm}$.

\section{Dona Joelma}

Figura 4 - Construção de brinquedo

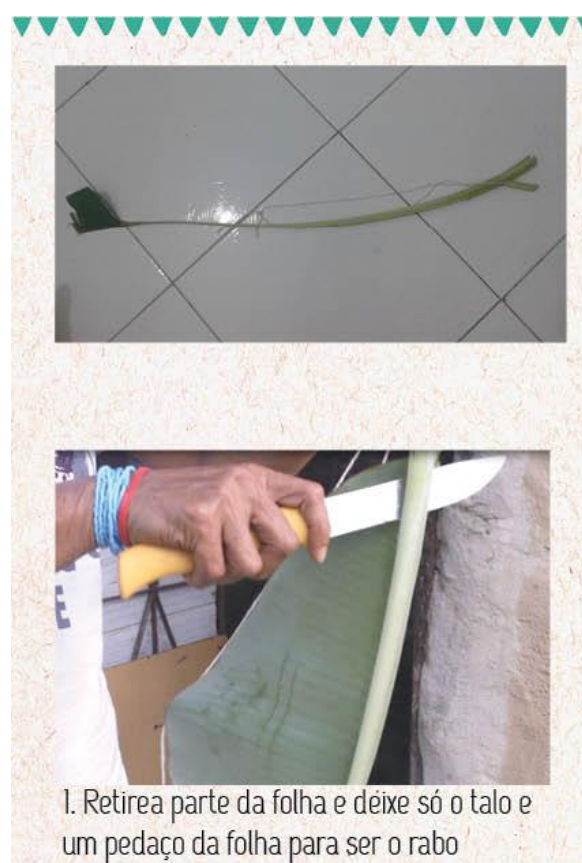

\section{Cavalinho de folha de bananeira}

\section{Materiais: \\ - I folha de bananeira \\ - Im de barbante}

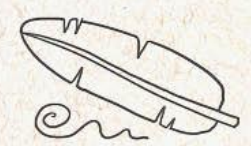

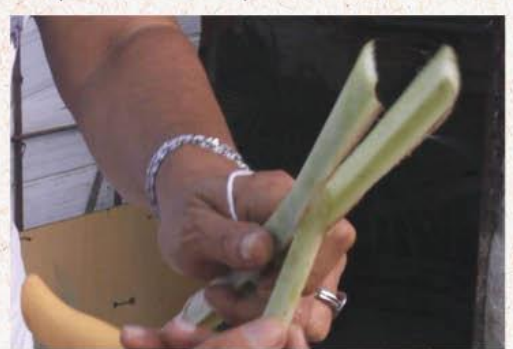

3. Abaixe o focinho

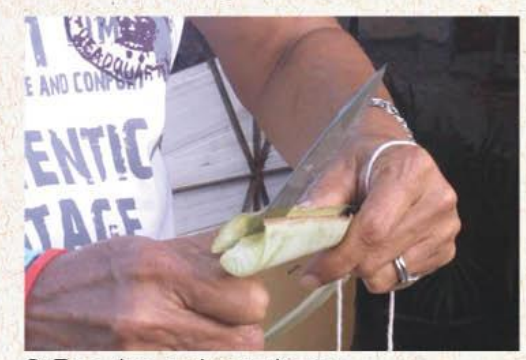

2. Faça dois cortes verticais na parte superior

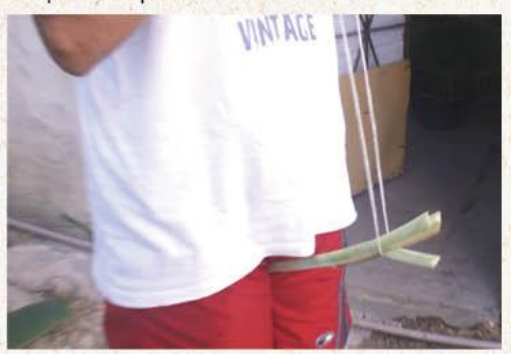

4. Amarre um barbante e monte 


\section{Cenário e Influências socioculturais}

Dona Joelma nasceu em Mapele e veio morar em Salvador aos 8 anos. Seu envolvimento com a natureza é percebido através do aproveitamento de cipós, folhas de bananeira e galhos e o mais interessante é o envolvimento em brincadeiras com o mar e brinquedos específicos da vida marítima como a jangada de bananeira.

Já a influência cultural de Dona Joelma é sentida no frequente contato com a natureza. Esse envolvimento desde cedo com o marisco promulgou uma conexão com a vida marítima, pois ela inventava jangadas para brincar e é marisqueira até hoje. Já trabalhou em outras funções como cordeira de blocos carnavalescos, faxineira, vendedora de água, mas o trabalho com o marisco é o que mais gosta e que faz com maior prazer.

Em seus brinquedos percebe-se a conexão entre os significados dos conceitos de Thompson (1998) e os significados que Dona Joelma pretendia passar. Assim como "as formas simbólicas são construções que tipicamente representam algo, referem-se a algo, dizem algo sobre alguma coisa" (Thompson, p.190, 1998), o entendimento desse conceito refere-se ao objetivo de quem constrói uma forma simbólica. Como Dona Joelma construía cavalinhos, ela não apenas pensava em montar no cavalo e imaginar a brincadeira, ela também pensava na estética. Isto significa que ela se preocupava que seu cavalo aparentasse como tal e para isso ela fazia os cortes verticais para marcar uma face bem definida com orelhas e focinho.

\section{Fatores ambientais}

Ao se aprofundar na conversa, ela revelou que seu brinquedo favorito é o cavalinho de folha de bananeira devido à facilidade de encontrar material porque assim todas as crianças presentes podiam fazer e brincar ao mesmo tempo. Infelizmente não é um brinquedo durável, pois a folha resseca no mesmo dia, mas expõe-se a capacidade dela em construir um brinquedo de simples confecção e com baixíssimo impacto ambiental. Apresenta-se ao designer a importância de buscar meios sustentáveis não só no uso de materiais, mas também na criação de objetos com simples montagem que reduz a utilização de muitas máquinas para chegar ao resultado final.

Tipologia e ergonomia

O cavalinho é o brinquedo que gostava de fazer quando não estava no mar, o que demonstra a busca contínua em permanecer atrelada à natureza. $\mathrm{O}$ cavalinho tem cabeça feita a partir de dois cortes na lateral do caule de uma folha de bananeira e ao abaixar a parte central têm-se o focinho e duas orelhas em pé. A parte de folha é quase toda arrancada deixando apenas o que seria a crina e o rabo. Sua extensão alongada mede $80 \mathrm{~cm}$.

\section{CONCLUSÃO}

Após o longo caminho percorrido percebeu-se como os brinquedos artesanais podem ser analisados em diferentes âmbitos que interagem entre si e são fundamentais para entender que o ser humano cria influenciado pelo ambiente em que vive. Percebeu-se que as criações das marisqueiras possuem uma relação intrínseca com sua cultura, com o que vê e imagina, e quando faz seus próprios brinquedos.

Estudar sobre o grupo de marisqueiras revelou-se como uma troca de conhecimentos 
entre pesquisadora e pesquisadas porque elas ensinaram como interagiam com a natureza enquanto essa pesquisa relembrou memórias e alegrias. Refazer os brinquedos foi crucial para compreender sua construção e poder analisá-los através do Design. Dessa forma, foi possível fazer uma relação entre design, cultura e a prática artesanal de fazer brinquedos ao investigar como os brinquedos artesanais eram feitos.

Considerando que essa produção de brinquedos artesanais se utiliza de materiais e tecnologias alternativas, o design vernacular mostrou o caminho para validar que as pessoas empenham seus saberes nativos e são capazes de agir criativamente em prol de uma necessidade específica. Até mesmo as crianças, indivíduos em fase de desenvolvimento, atendem a esse estímulo e isso ocorre como ferramenta para suprir uma necessidade lúdica e imaginária.

O interessante das técnicas utilizadas na produção desses brinquedos deve-se ao meio como foram alcançadas. Devido à restrição do acesso a matérias-primas mais eficientes, a produção ocorre a partir de materiais inesperados por serem economicamente viáveis e que apresentam notório desenvolvimento criativo. Influenciadas pelo contexto sociocultural em que as marisqueiras estão inseridas, reafirma-se a capacidade criativa inata de todo indivíduo.

\section{REFERÊNCIAS}

BOUFLEUR, Rodrigo Naumann. A questão da gambiarra. 2006. Dissertação (Mestrado). Faculdade de Arquitetura e Urbanismo da Universidade de São Paulo. São Paulo, 2006. 148 f.

DENIS, Rafael. Design para um mundo complexo. São Paulo: Cosac Naify 2012.

DENIS, Rafael. Design, cultura material e o fetichismo dos objetos. In Arcos, volume I, número único, 1998, p. 15-38. Disponível em: <http://www.esdi.uerj.br/arcos/arcos-01/0102.artigo_rafael(14a39).pdf>. Acesso em: 19/06/2012.

FINIZOLA, Fátima; COUTINHO, Solange G.; CAVALCANTI, Virgínia P. Vernacular design: a discussion on its concept. In: FARIAS, Priscila Lena; CALVERA, Anna; BRAGA, Marcos da Costa; SCHINCARIOL, Zuleica (Ed.). Design frontiers: territories, concepts, technologies [ICDHS 2012 - 8th Conference of the International Committee for Design History \& Design Studies]. São Paulo: Blucher, 2012.

MEFANO, Ligia. O Design de Brinquedos no Brasil: Uma arqueologia do projeto e suas origens. 2005. 164 f. Dissertação (Mestrado) - Curso de Design, Departamento de Artes \& Design, Puc-rio, Rio de Janeiro, 2005.

MORAES, Dijon de. Análise do design brasileiro: entre mimese e mestiçagem. São Paulo: Edgar Blucher, 2006.

MORAES, Dijon de. Metaprojeto. SP: Edgar Blucher, 2010.

PACEY, Philip. 'Anyone Designing Anything?' Non-Professional Designers and the History of Design Source: Journal of Design History, Vol. 5, No. 3 (1992), pp. 217-225 Published by: Oxford University Press on behalf of Design History Society

RAPOPORT, Amos. Spontaneous Settlements as Vernacular Design in Patton, Carl V. Spontaneous Shelter: International Perspectives and Prospects. 1a Ed, USA: Temple University Press, 1987.

ZUMBANO, Raquel. Brincando na história. in PRIORE, Mary del (org). História das Crianças no Brasil. SP: Contexto, 1991. 